Corpo e educação: uma reflexão sobre a história do corpo e suas implicações para as práticas corporais contemporâneas desenvolvidas no contexto escolar*

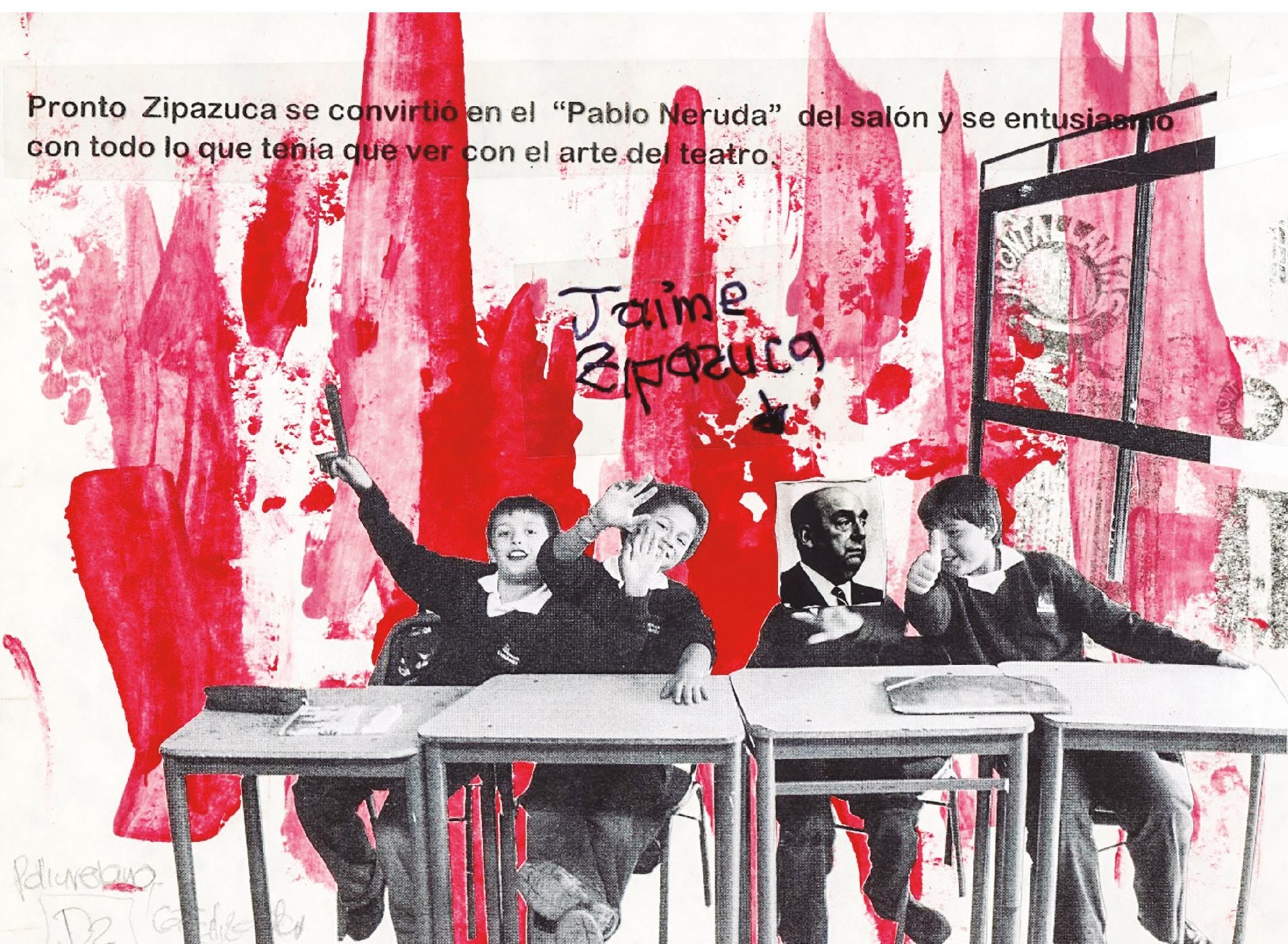




\title{
Cuerpo y educación: una reflexión sobre la historia del cuerpo y sus implicaciones para las prácticas corporales contemporáneas desarrolladas en el contexto escolar
}

\section{Body and education: a reflection on the history of the body and its implications for contemporary body practices developed in the school context}

\author{
Tânia Roberta da Silva** \\ Secretaria de Educación Básica del Estado de Ceará, Brasil \\ Correo electrónico: taniabetinha@gmail.com.br \\ Revista Corpo-grafías: Estudios críticos de y desde los cuerpos / Volumen 4 - Número 4 / Enero - diciembre de 2017 / \\ ISSN impreso 2390-0288, ISSN digital 2590-9398 / Bogotá, D.C., Colombia / pp. 52-75. \\ Fecha de recepción: 8 de noviembre de 2016 \\ Fecha de aceptación: 28 de noviembre de 2016 \\ Doi: https://doi.org/10.14483/25909398.13662 \\ Cómo citar este artículo: Silva, T. (2017, enero-diciembre). Corpo e educação: uma reflexão sobre a história do corpo \\ e suas implicações para as práticas corporais contemporâneas desenvolvidas no contexto escolar. Revista Corpo- \\ grafías: Estudios críticos de y desde los cuerpos, 4(4), pp. 52-75 / ISSN 2390-0288. \\ *Artículo de investigación: este artículo es resultado de un proyecto de investigación realizado en el ámbito de dos \\ escuelas públicas de Fortaleza, capital del Estado de Ceará, Brasil, que pertenecen a redes municipales y redes de \\ enseñanza del Estado. \\ ** Maestra en Evaluación de Políticas Públicas por la Universidad Federal de Ceará, especialista en Administración \\ Escolar por la Universidad del Valle del Acaraú (UVA). Fue coordinadora Escolar y directora general en la Secretaría \\ Municipal y Estadual de Educación del Ceará, participa en el Grupo de Investigación sobre estado, políticas sociales y \\ educación brasileña (GEPE) de la Universidad Federal de Alagoas.
}

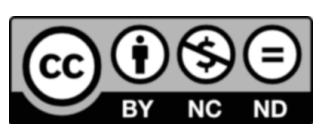

Todas las imágenes de este artículo pertenecen a la autora Natalia Amaya García.

Título: De la serie Neruda Vivía en el Veinte

Técnica: Collage y Dibujo

Dimensiones: $28 \mathrm{~cm} \times 20.5 \mathrm{~cm}$ 


\section{Resumo}

Este artigo é resultado de um projeto de pesquisa realizada no âmbito de duas escolas públicas de Fortaleza, capital do Ceará- Brasil, sendo uma da rede municipal e outra da rede estadual de ensino e tem como objetivo situar uma reflexão acerca das práticas corporais realizadas nas escolas no contexto contemporâneo, partindo dos pressupostos teóricos que embasaram estas práticas numa perspectiva histórica, social e local. Dessa forma busca identificar os significados atribuídos ao corpo através da história e dos processos sociais e culturais no contexto local, com o intuito de relacioná-los às práticas corporais desenvolvidas nos espaços educacionais, mais precisamente na disciplina de educação física.

Palavras- chave: corpo; educação; práticas corporais.

\section{Resumen}

Este artículo es resultado de un proyecto de investigación realizado en el ámbito de dos escuelas Públicas de Fortaleza, capital del Estado de Ceará- Brasil, siendo una de las redes municipales y redes de enseñanza del Estado. Ha tenido como objetivo reflexionar sobre las prácticas corporales realizadas en las escuelas en el contexto contemporáneo, partiendo de presupuestos teóricos que analizarán estas prácticas en una perspectiva histórica y social. Así, se buscó identificar los significados atribuidos al cuerpo a través de la historia y de procesos sociales y culturales, con la intención de relacionarlos a las prácticas corporales desarrolladas en los espacios educacionales, específicamente en la asignatura de educación física. Palabras clave: cuerpo; educación, prácticas corporales.

\section{Abstract}

This article is the result of a research project carried out in two public schools in Fortaleza, capital of Ceará in Brazil - one of which belonging to the municipal education network and another to the state education network. Its objective was to establish a reflection on the corporal practices carried out in schools in the contemporary context, having as a starting point the theoretical presuppositions on which these practices were based in a historical and social perspective. This way, we sought to identify the meanings attributed to the body through history and through social and cultural processes, in order to relate them to the corporal practices developed in educational spaces, but precisely those developed in the discipline of physical education.

Keywords: body, education, corporal practices. 


\section{Introdução}

Meu papel- mas esse é um termo muito pomposo - é o de mostrar às pessoas que elas são muito mais livres do que pensam ser; que elas tem por verdadeiros, por evidentes, alguns temas que foram fabricados num momento particular da história, e que essa suposta evidência pode ser criticada e destruída.

Michel Foucault

Este artigo caracteriza-se por uma exposição dos pressupostos práticos e teóricos acerca de como se dão as práticas corporais nas escolas públicas em nosso país, no contexto local do estado do Ceará no sentido de suscitar uma reflexão sobre estas práticas a partir das teorias que as sustentaram no decorrer dos tempos, objetivando reconhecêlas como fruto dos processos históricos e sociais nos quais foram gestadas e ancoradas possibilitando a ampliação e aprofundamento sobre essas práticas, tendo em vista que, embora tenha ocorrido uma relativa evolução nesse campo, perceptíveis em diretrizes curriculares e preconizados em alguns aparatos legislativos que orientam os processos educacionais, o que tem se observado na prática é tão somente a repetição de padrões e normas ainda remanescentes do positivismo enquanto método científico, tendo sido determinante para as atividades disciplinares e que no tocante à educação física e ao conjunto de suas práticas corporais consideram contemplar o desenvolvimento do corpo de forma integral, a formação acadêmica e, consequentemente a socialização das crianças e adolescentes que as praticam no âmbito escolar.

O principal objetivo consiste em situar esta reflexão acerca do corpo dentro de uma perspectiva histórica, social em um contexto local, e suas implicações para as práticas corporais desenvolvidas nas escolas públicas, que, atendem a um público específico que em sua maioria vem das classes mais desfavorecidas da sociedade e residem nas periferias, que, por sua vez se constituem em espaços quase sempre negligenciados pelo poder público em termos de atendimento básicos à essas populações.

Nesse contexto delimitaremos um arcabouço teórico sobre o corpo e apresentaremos algumas considerações acerca das práticas corporais que possibilitaram seu arranjo conforme a conhecemos nos dias atuais destacando as pesquisas realizadas e a materialidade empírica delineada a partir das mesmas. 


\section{Pressupostos teóricos A história do corpo e seus desdobramentos}

A produção do corpo no projeto moderno ocidental é marcada por uma política que investiu predominantemente na domesticação da experiência do corpo. Foucault (2009) compreende esse período, ou este conjunto de tecnologias de poder agindo sobre o corpo como a "sociedade disciplinar", que ele caracteriza como movimentos que ocorreram de um período a outro da sociedade e que foram gradativamente modificando as formas de dominação, buscando através do disciplinamento manter os indivíduos aquém dos seus direitos conformando-os às instituições e sob o poder da burguesia que à medida que ascendia promovia a derrocada de valores na sociedade. Segundo Veiga (2016) Foucault não entende por dominação uma ação global de um indivíduo sobre outro ou um grupo de indivíduos sobre outro e sim "as múltiplas formas de dominação que podem ser exercidas na sociedade em todas as direções e sentidos (VEIGA, 2016, p.118)." Foucault considera que este processo de dominação ocorreu ainda na época clássica quando se deu a descoberta do corpo como objeto e alvo de poder (Foucault, 2009) neste período se encontraria na literatura com bastante facilidade fortes indicações voltadas para o corpo, nas palavras de Foucault "ao corpo que se manipula, se modela, se treina, que obedece, responde, se torna hábil ou cujas forças se multiplicam (p. 132) dentre essa literatura destaca" O Homem-máquina" de La Mettrie, cujo conteúdo, segundo Foucault, é praticamente uma teoria generalizada do adestramento do corpo trazendo a noção deste, como "dócil" o que para o ele "é dócil um corpo que pode ser submetido, utilizado, transformado e aperfeiçoado (Foucault, 2009)."

O autor nos traz o entendimento de que em qualquer sociedade o corpo é colocado como um objeto de poder que se encontra preso por obrigações e limitações que lhes são impostas e que o que se diferencia na passagem de um período para outro são as técnicas e formas de aprisionamento deste corpo.

Assim, no século XVIII esse "corpo dócil" continua sendo objeto, porém numa perspectiva diferente de controle, passando de um significado relacionado à linguagem e ao comportamento para uma coerção focada mais na eficácia dos movimentos dentro de um determinado tempo e espaço.

Para Foucault (2009):

Esses métodos que permitem o controle minucioso das operações do corpo, que realizam a sujeição constante de suas forças e lhes impõem uma relação de docilidade-utilidade, são o que podemos chamar as "disciplinas". (...) o momento histórico das disciplinas é o momento em que nasce uma arte do corpo humano, que visa não unicamente o aumento de suas habilidades ou aprofundar sua sujeição, mas a formação de uma relação que no mesmo mecanismo o torna tanto mais obediente quanto é mais útil e inversamente. Forma-se então uma política das coerções que são um trabalho sobre o corpo, (...) A disciplina fabrica assim corpos submissos e exercitados, corpos “dóceis” (2009, p. 133). 
Desse modo, as instituições envolvidas nesse processo- a fábrica, o exercito, hospitais e instituições educacionais - foram conformando dispositivos que articulavam saberes através do controle do uso do tempo e do espaço. Nas instituições escolares, desde o século XVIII os alunos eram ordenados em filas, período esse em que se começa a definir, conforme Foucault (2009) a grande forma de repartição dos indivíduos na ordem escolar nesses espaços alinhados eles são distribuídos conforme seus saberes, suas capacidades, ou sendo ainda repartidos conforme os valores e os méritos.

Para o autor a organização de um espaço serial foi uma das grandes modificações técnicas do ensino elementar. Determinados lugares individuais tornou possível o controle de cada um e o trabalho simultâneo de todos. Organizou uma nova economia do tempo de aprendizagem. A partir dessa organização o espaço escolar passa a funcionar como um maquinário de engrenagens perfeitas que combina tempo e espaço e onde não só se ensina, mas impõe-se hierarquias, sendo possível a vigilância e a recompensa (Foucault, 2009).

Dessa forma o século XVIII traz um cenário ao mesmo tempo de técnicas de poder e de saber. O saber entra como um processo que conduz o poder, tornando esse mecanismo naturalizado através das relações em que todos participam e em que todos são ativos, possibilitando uma forma de transmissão em que há o consentimento de todos e a escola é um exemplo disto (Veiga, 2016), mas nesse processo de aproximação do poder com o saber, para Foucault o poder é constituído pelas relações de força, enquanto que o saber pelas relações de forma; o poder é algo muitas vezes imperceptível, mas, que permeia as relações de maneira fugaz, evanescente. O saber estabelece-se através dos elementos formais, "da matéria, dos conteúdos; é possível ao saber ser ensinado e apreendido. Para Veiga (2016) essa relação se dá sobre e pelo sujeito através do discurso que no pensamento de Foucault é“ justamente no discurso que vêm a se articular poder e saber" (p. 128).

Veiga (2016) ancorado em Foucault assinala que essa produção de corpos vai além de uma dimensão psicológica para dar origem a corpos que necessariamente têm de participar e que, por isso, são corpos políticos (p.116) essa participação simultânea com o intuito de se disciplinar de forma homogênea os indivíduos sociais encontra possibilidade de afirmar-se através de espaços institucionalizados e que como nos coloca Foucault:

As disciplinas, organizando as "celas", os "lugares" e as fileiras" criam espaços complexos: ao mesmo tempo arquiteturais, funcionais e hierárquicos. São espaços que realizam a fixação e permitem a circulação; recortam segmentos individuais e estabelecem ligações operatórias; marcam lugares e indicam valores; garantem a obediência do indivíduo, mas também uma melhor economia do tempo e dos gestos. A primeira operação da disciplina é então a constituição de "quadros vivos" e (...) o quadro, no século XVIII, é ao mesmo tempo uma técnica de poder e um processo de saber (Foucault, 2009, pp. 142-143). 
Considerando o pensamento do autor sobre as determinações disciplinares que permearam os séculos anteriores, o século XIX se coloca sob uma base disciplinar que Foucault a descreve como uma tática e que através dela se permite ao mesmo tempo colocar o indivíduo como indivíduo em sua singularidade e colocar ordem a partir de uma multiplicidade dada e é essa dimensão que passa no começo do século XIX a permitir os mecanismos disciplinares que favorecem o controle como a fixação de horários escolares, o controle de atividades e outros.

Tomando como aporte esse pensamento acerca da disciplina, analisemos com Soares (2005) o processo que estruturou os saberes na educação do corpo e as tecnologias de poder que atravessaram tal processo no início do século XIX, quando grande parte das atividades corporais eram manifestações vivenciadas por artistas circenses, de

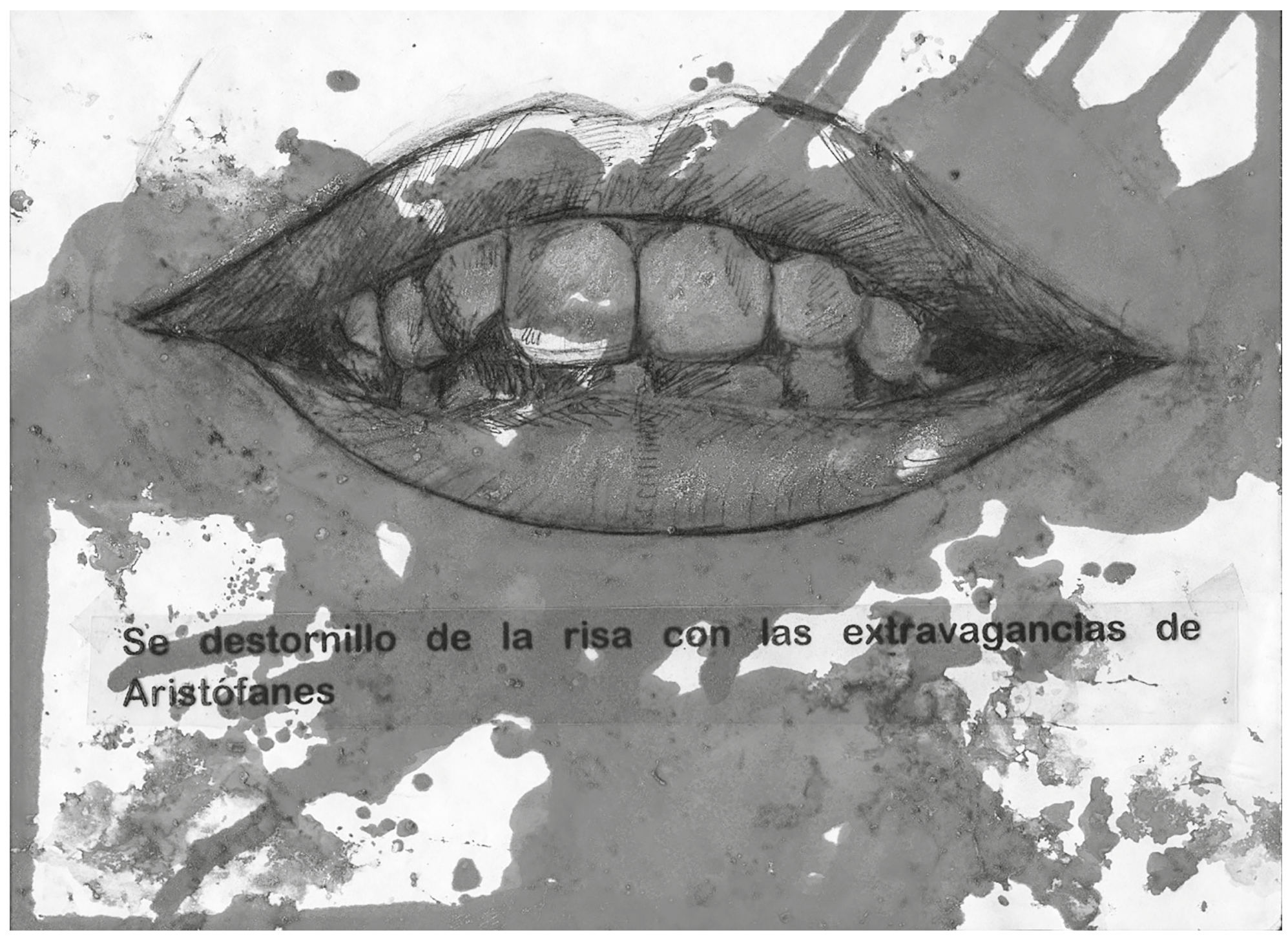


teatros de ruas e feiras que praticavam diversas destas atividades de forma livre e divertida através de suas cambalhotas, acrobacias e outras práticas que fomentavam no povo o riso, a alegria e a descontração. Estas formas emergiam de um contexto mais libertário de corpo, onde o intuito era despertar a curiosidade e o espanto dos espectadores.

Essas atividades foram expressivas na Idade Média e no período do Renascimento, e tinham como único objetivo divertir aqueles que as contemplavam.

Com o advento da ciência positivista baseada na racionalidade e no uso de técnicas científicas, bem como o surgimento da sociedade burguesa que buscava consolidar-se enquanto classe social dominante urge a necessidade de busca de mecanismos de controle sobre a população o que se procurou fazer através da disseminação da moral e dos bons costumes, pois, se acreditava ter relação direta com o indivíduo a partir dos exercícios com o corpo.

Neste século, portanto, caracterizado pela ascensão da sociedade burguesa, Foucault (2009) assinala como o período que ocorrera uma mudança gradativa nos mecanismos de transmissão de poder que se tornaram cada vez mais sutis, neste sentido a nova classe social sob a égide do capitalismo passa a aspirar um novo homem capaz de adaptar-se às exigências do capital e, conseqüentemente, à consolidação dessa nova classe que ditava seus princípios no conjunto de práticas sociais a partir dos parâmetros científicos da ciência positivista.

Forma-se, então, no século XIX, uma pedagogia do gesto e da vontade, configurando-se assim, uma "educação do corpo". A ginástica, com suas prescrições, enquadra-se nesta pedagogia e faz-se portadora de preceitos e normas, ganha espaço e se afirma como forma específica de treinamento do corpo e do desejo de criar um novo homem compondo a "pedagogia do signo e do gesto (Soares, 2005, p.29)".

Ao longo do século XIX, portanto, a ginástica vem se consolidar como uma prática que tem uma relação com a utilidade, no sentido de desprezar as práticas circenses que eram tidas como inúteis, nessa nova composição o corpo passa a ser apresentado através de ações que demonstram firmeza, controle, e que possa ser útil à vida cotidiana. Dessa forma vai se estabelecendo e se difundindo uma identidade da ginástica com a ordem, onde tudo se materializa de uma forma determinada e pautada no cientificismo institucionalizado.

As práticas circenses de outrora que divertiam o público passaram a ser vistas com maus olhos, consideradas como desleixo do corpo e inadequadas para a formação moral do indivíduo, descortinando-se assim, assinala Soares (2005) uma luta árdua entre a ascendente burguesia que se dizia ordeira, limpa, firme, pautada em uma fixidez incontestável e este "outro" que a tudo se permitia e que para transformá-lo seria necessário uma mudança profunda nos hábitos, crendices e costumes que apreciava a maioria da população do início deste século. 
A ginástica é, portanto, constitutiva de uma mentalidade que se destaca por seu caráter disciplinador, caráter este, que, como já visto em Foucault, emerge como elemento que vai dentro de um determinado tempo e espaço em sua dualidade corpo-objeto, estabelece a relação que o corpo deve manter com o objeto como uma perfeita engrenagem que limita, atrofia permitindo o seguimento de um padrão específico.

Nascida desse entendimento a ginástica como a conhecemos hoje exigiu uma ordenação e um método compatíveis com sua aplicabilidade, ainda é importante destacar que houve no século XIX, inúmeras tentativas de se ampliar essas práticas corporais- a ginástica- de modo a aplicá-la a toda população urbana que crescia exponencialmente e, conforme Soares (2005) à medida que se tornava mais numerosa, mais "perigosa" aos objetivos do capital.

Mas como seria possível ampliar tais práticas de modo que as mesmas estivessem ao alcance de todos, como método de conformação e eliminação de práticas d’antes aplicadas? A ginástica então deveria ser pensada pelo aparato científico disponível e assim colocada em igualdade com outras práticas sociais, explicada e sistematizada. Devia tornar-se obrigatória para a sociedade em geral, bem como prática regular em todos os currículos escolares (Soares, 2005, P. 22).

O marco desse projeto de ginástica veio a partir do Movimento Ginástico Europeu e com ele o primeiro esboço do que denominamos hoje, educação física, que se consolidou nos ginásios, passando posteriormente, a ser praticada e ensinada nas diversas escolas do Ocidente.

Um dos instituidores da ginástica foi o coronel Amoros (Francisco Amoros y Odeano, 1838) que difundiu na França os cânones da ginástica elementar baseados em suas experiências militares, em sua educação e em seus estudos sobre a mecânica, pensou a ginástica inserida no conjunto de normas de conduta moral.

Soares (2005) ressalta que a ginástica elementar era constituída por marchas, corridas, flexionamentos graduais de braços e pernas, exercícios de equilíbrio, de força individual e destrezas múltiplas. Seu objetivo: educar moralmente seus praticantes. (p.50).

Embora Amoros tivesse consciência que toda a aparelhagem para a prática dos exercícios tivessem sido utilizadas por acrobatas e fulâmbulos durante a Idade Média e Renascimento, seu maior desejo era constituir um projeto com bases e determinações científicas baseado especificamente nas leis da mecânica, mantendo-se distante das práticas circenses impregnados de preceitos morais e ideológicos das elites francesas que impunham-lhe a obrigatoriedade de acentuar este distanciamento e concomitantemente aproximar seus métodos à ciência positiva firmando os preceitos da então sociedade burguesa. 
Para o ideário burguês que se pretendia universal assinala Soares (2005):

Tudo teria utilidade, ciência e técnica como formas específicas do saber determinariam os ângulos corretos de cada alavanca que possui o corpo visto como máquina: indicarão o quanto da força é preciso imprimir para um impulso e um salto; quais as partes do corpo (totalmente esquadrinhado) são mais resistentes. As atividades corporais então, paulatinamente, são classificadas, analisadas e meticulosamente redesenhadas pelas mãos do homem da ciência.(p.58).

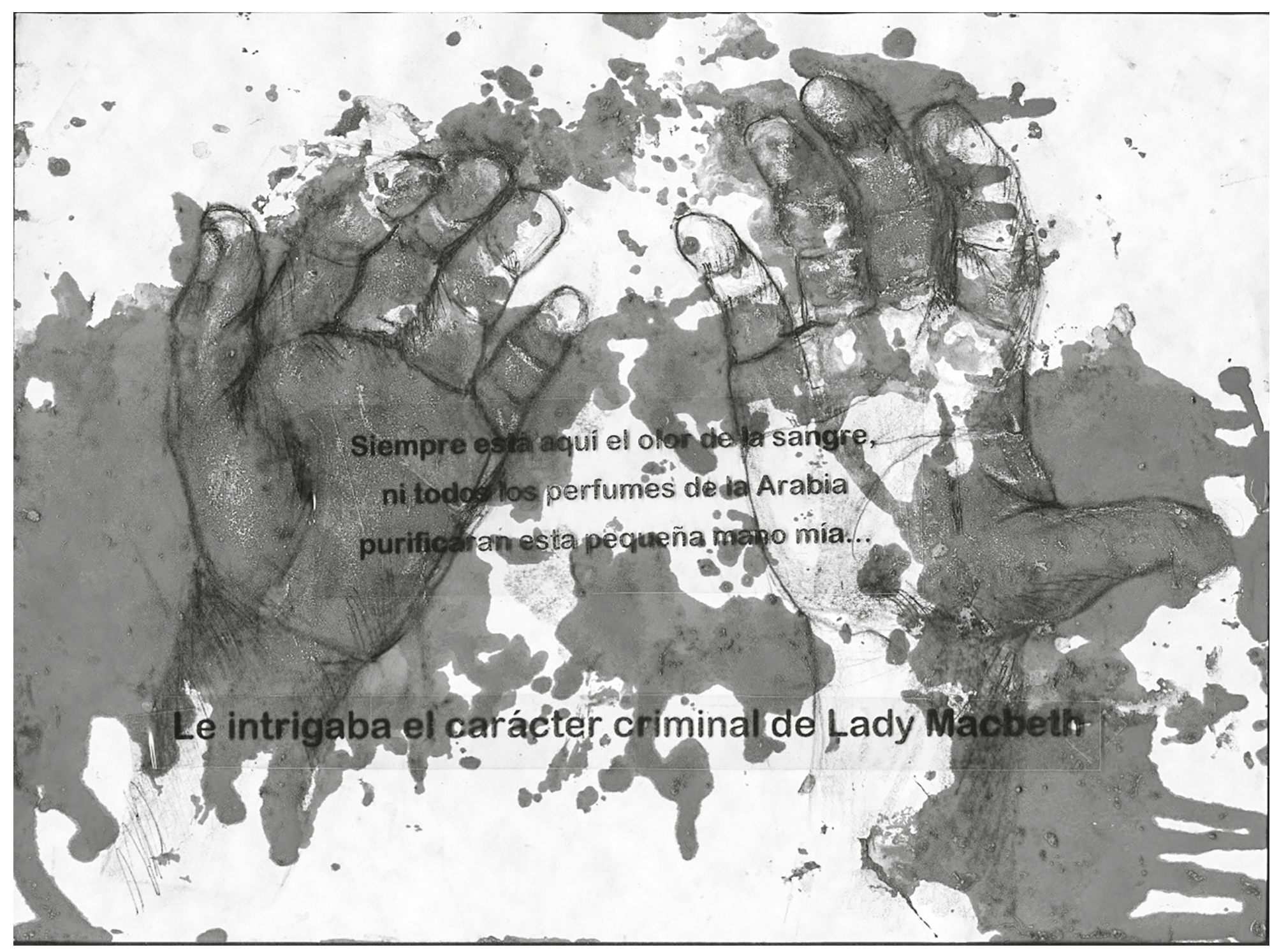


Para a autora "vivia-se o momento em que se almejava criar o corpo civilizado". (p.58).

Elias observa que o processo civilizatório consistiu-se num rico e detalhado código de gestos e atos corporais considerados "civilizados" cujos movimentos deveriam ser absorvidos pelos indivíduos na sociedade (Elias, 1993, apud Soares, 2006).

Dessa forma, as práticas corporais foram sendo moldadas e suas principais características constituíram-se por precisão, sistematização, rigor, experimentação e controle. Soares (2005) aponta que este foi o universo terminológico que determinou o conjunto de atividades corporais que ainda vigora nos dias atuais rompendo radicalmente com a forma d'antes praticada, livres e como rituais de viver (p.59).

Conforme a autora, da ideia predominante de modelagem do corpo caminha-se para a ideia de adestramento do corpo, que a partir dos conceitos da termodinâmica encontra bases científicas para se reestruturar dentro dessa nova concepção que a autora apresenta como "corpo adestrado".

\section{Novas perspectivas históricas $O$ corpo no centro das pesquisas}

Com base no percurso teórico apresentado, podemos perceber que o corpo vai se tornando cada vez mais objeto de pesquisas, ressaltando sua utilização para a vida cotidiana e principalmente sobre a vida no trabalho, coadunando com Foucault (2009) podemos focar nosso olhar para a "sociedade disciplinar" no que diz respeito à instituição escola que é o objeto desta pesquisa e que conforme o autor traz a disciplina não referindo -se à instituição em si, mas a uma espécie de poder, que comporta todo um aparato de instrumentos e técnicas de modo a ser exercido e que têm nas instituições um espaço de dominação por excelência.

Dentro dessa perspectiva e considerando as práticas corporais realizadas nas escolas, podemos perceber que estas práticas sofreram influência direta deste processo disciplinar apontado por Foucault (2009) e que tem nos diversos compêndios apontados por outros autores como Soares (2005) que discute a questão do corpo, Elias (1993) que caracteriza o processo civilizatório, sua instrução pautada sob a ótica desses estudos e pesquisas que ocorreram mais precisamente na segunda metade do século XIX, com o advento do processo de industrialização e a consolidação da burguesia, e que, tiveram implicações substanciais no modo como as utilizamos na contemporaneidade. 
Mediante esta afirmação buscamos refletir e pensar essas práticas como resultado dos processos que as originaram perfazendo seu processo histórico e analisando-as no contexto escolar local em duas instituições públicas das redes municipal e estadual do Ceará respectivamente, de modo a compreender as nuances que ainda refletem o caráter da disciplina enquanto mecanismo de poder dentro da instituição escola.

A pesquisa tem como objetivos:

1) compreender o processo histórico e social acerca das práticas corporais trabalhadas na escola;

2) refletir sobre o papel do professor de educação física na contemporaneidade; e

3) identificar as práticas corporais utilizadas no contexto escolar.

Para tanto, faz-se necessário adentrar no contexto histórico e social que implicaram o processo de desenvolvimento das práticas corporais sob a análise das pesquisas de estudiosos que a referendaram no campo das ciências, culminando na educação física como disciplina curricular da educação básica.

Com o processo de industrialização a necessidade do manuseio das máquinas, bem como as preocupações com o aumento da produtividade, levaram as pesquisas a avançar sobre o estudo da capacidade de velocidade dos movimentos e do uso da força.

Surge daí uma nova ciência a ergonomia,

(...) ciência da fadiga, das relações entre o homem e a máquina no processo de trabalho. O corpo humano é visto então, como "um conjunto mecânico animado por um motor cuja combustão invisível deve ganhar em eficiência que pode ser medida" (Soares, 2005, p.86).

No contexto industrial, passa-se a utilizar os estudos e as pesquisas sobre os gestos e as posturas de forma a fazer crescer a eficácia funcional, conforme Soares (2005) era nítido o fascínio pela construção de modelos fixos e generalizados que buscasse atender as necessidades do trabalho.

Levado por esse fascínio, Demeny (citado por Soares, 2005, p.88) dedica-se aos estudos da fisiologia e amplia seus estudos para uma educação do movimento e passa a aprimorar o ensino da ginástica a partir do "gesto educado", do "domínio das forças" e sua distribuição pelo corpo, da postura ereta. A ginástica é a grande responsável pela visibilidade deste corpo educado (Soares, 2005, p.88). 
As práticas corporais pesquisadas por Marey e Demeny, continuaram amparadas nas descobertas científicas, aperfeiçoadas pelas leis da termodinâmica e da fisiologia, sendo as mesmas orientadas num contexto de saúde, higienização sem, contudo, desprezar o sentido da moral e dos bons costumes o que, de certo modo, contrastava com a realidade social que se estendia pelas comunidades trabalhadoras em sua maioria nos serviços braçais, nas indústrias, fábricas que exigiam do trabalhador uma postura adequada ao maquinário ou a exploração de minas de carvão dentre outras.

Toda a teoria desenvolvida por Demeny na segunda metade do século XIX foi formatada sob a égide da ciência positivista, o mesmo desprezava todo e qualquer ensinamento que não pudesse ser constatado ou provado, destacava a necessidade de regras fixas para ele "só há um método aceito no campo da biologia que é o método experimental e é a ele que a educação física deve recorrer para afirmar-se no campo da ciência (Soares, 2005, p. 129)”.

Assinala a autora a educação física consolidada no século XIX, encarna o espírito desse século e diante do apoio de políticas oficiais dada ao grupo de Demeny se consagra influenciando também a educação física escolar, que ainda hoje traz o rigor dos exercícios aliados a um campo teórico de definições que permitem adequar cada um dos exercícios a um objetivo do plano curricular que são aplicados nas escolas.

Quando direcionamos nossas observações para a realidade do que ocorre nas aulas de educação física na escola pública nos deparamos com aulas práticas cujas atividades baseiam-se numa proposta curricular que ainda remetese ao corpo a partir de uma visão da biologia, privilegiam as atividades esportivas, alguns jogos e brincadeiras." A influência do esporte no sistema escolar é de tal magnitude que temos não o esporte da escola, mas sim o esporte na escola (PCN, 2000, p. 34).

Em uma das escolas observadas, E.M de Educação Infantil em Fortaleza/CE os professores trabalham as práticas de educação física realizando atividades de recreação, mas não possuem preparação adequada para o trabalho com as práticas corporais deixando evidente que esta etapa da educação fica à mercê do que o professor considera adequado.

Na maioria das escolas o trabalho com o corpo obedece ao padrão curricular estabelecido para a faixa etária e que compõe o mesmo rigor pedagógico através dos exercícios, de jogos, brincadeiras e outros.

Considerando o pensamento de Daolio (1984, p. 25), para quem as associações ao corpo são frutos de uma dinâmica cultural particular, podemos inferir que as práticas corporais trabalhadas na educação física em nossas escolas, imprimem tão somente, a cultura das práticas pedagógicas tradicionais advindas de um currículo igualmente tradicional que orientam as atividades realizadas nestas escolas, e que são absorvidos ainda nas universidades igualmente limitadas. 
Segundo o autor, infelizmente no meio acadêmico e profissional da educação física, a mesma ainda é considerada de um ponto de vista puramente biológico, não sendo ainda compreendida de um ponto de vista antropológico, limitando a formação profissional. Quando se pensa em corpo livre, assinala o autor, "parece que se busca um corpo que não esteja escravizado ou moldado pelas regras sociais" (Daolio,1984,p.25).

Conforme ele, o corpo é uma síntese da cultura, porque expressa elementos específicos da sociedade do qual faz parte, a cultura vai sendo assimilada através do corpo que absorve os costumes e valores socialmente construídos num processo que ele denominou inCORPOração. Para ele, o indivíduo adquire um conteúdo cultural que se instala no corpo e no conjunto de suas expressões (Daolio, 1984, p. 25).

A afirmação acima, bem como nossa experiência no contexto da escola nos leva ao entendimento do quanto nossa prática docente e nossas relações com o corpo imprimem e expressam nossa cultura, neste sentido concordamos com o pensamento de Daolio (1984), transmitimos através de nosso corpo, por gestos, expressões, posturas, o que assimilamos no decorrer da nossa história de vida, sendo este comportamento refletido em nosso trabalho cotidiano.

Ora, se pensarmos em nosso diário de atividades culturais e esportivas que realizamos na nossa vida estudantil que nos foram repassadas como legítimas porque foram referendadas pela escola e que, portanto, têm relevância científica, cultural e social, poderemos compreender a intenção condicionante que nos é colocada no sentido de nos tornarmos"sociáveis" para atuarmos na sociedade em que vivemos como sujeitos de nossa história e "cidadãos plenos."

Esse pensar nos remete a imediata reflexão do que somos hoje enquanto corpos sociais, pelo que aprendemos, o que internalizamos e estruturamos a nossa postura, arraigada ao que acreditamos como verdade e que nos foram impostas por uma educação do corpo, "moldado" e "adestrado", para enfim sobrevivermos aos ditames sociais que nos aprisionam, nos embrutecem e nos condicionam ao pensamento comum que é experimentado e reproduzido cotidianamente conforme nossas práticas sociais e culturais.

Daolio ressalta que:

Todas as práticas institucionais que envolvem o corpo humano- e a educação física faz parte delas- sejam elas educativas, recreativas, reabilitadoras ou expressivas, devem ser pensadas num contexto que considere o homem sujeito da vida social. Entretanto, os profissionais da educação física cotidianamente, limitam- se ao uso de técnicas de como melhorar a postura, ter o corpo perfeito, andar adequado e etc. (p. 27). 
E reitera seu pensamento trazendo um conceito de Bracht (1992, p. 39):

"A materialidade corpórea foi historicamente construída e, portanto, existe uma cultura corporal, resultado de conhecimentos socialmente produzidos e historicamente acumulados pela humanidade (...)".

Neste sentido, nossa reflexão vai ao encontro do pensamento desses autores e de outro já referidos anteriormente como Focault (2009), corroborado por Kofes (1985) que, partindo de uma visão antropológica, coloca a necessidade de se questionar os discursos acerca do corpo, aliando este à sociedade no qual está inserido e, para tanto, ressalta

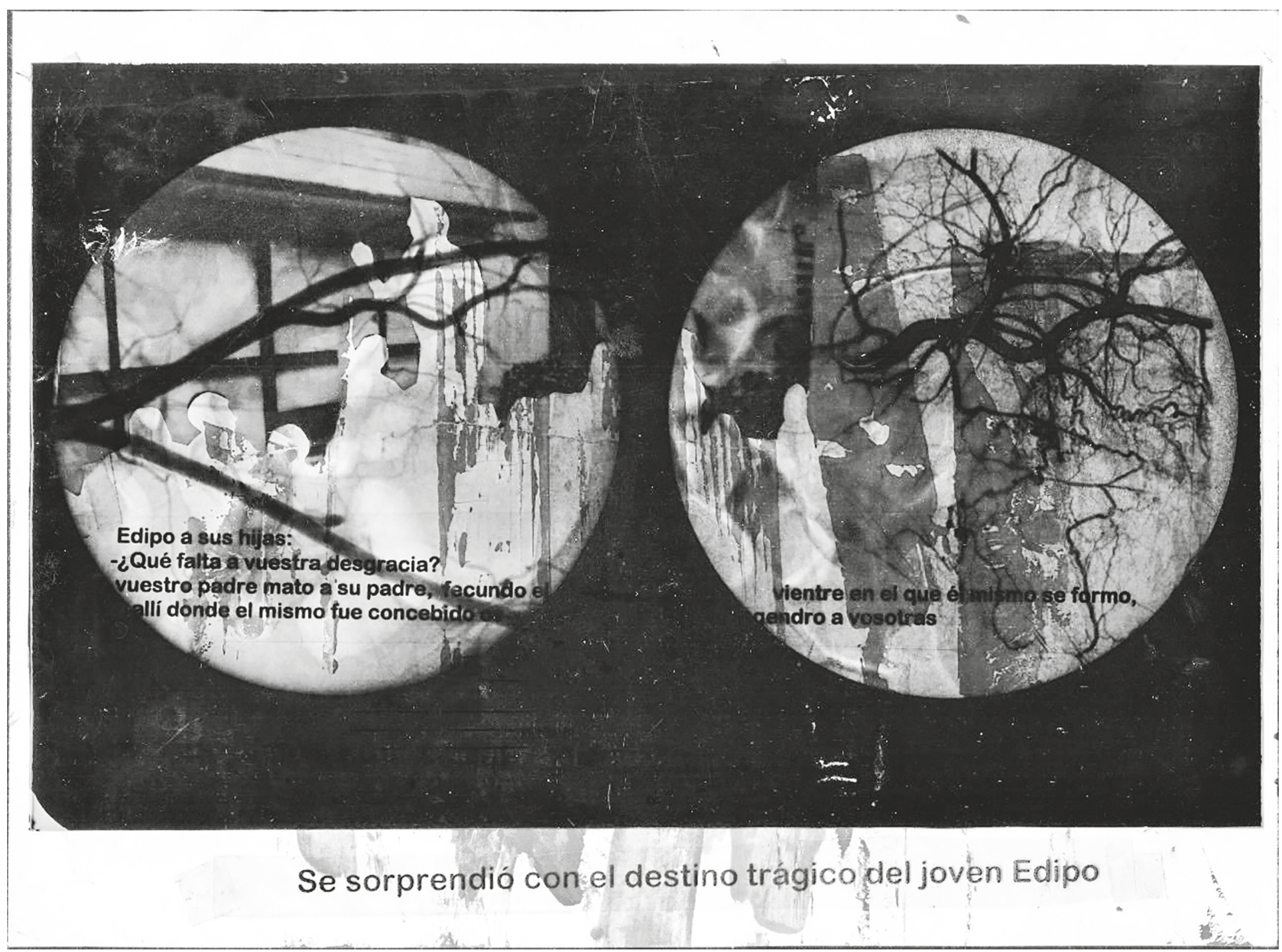


a importância de que mediante discussões sobre essa temática questionar-se sobre “(...) o que a sociedade está afirmando dos corpos? Que corpos? Que sociedade?" (p.57).

E Daolio (1984) acrescenta: Qual a representação de corpo que os professores de educação física possuem?

Para respondermos a esses questionamentos destacaremos o que a Lei de Diretrizes e Bases da Educação (LDB 9394/1996) traz sobre as finalidades dessa disciplina para o Ensino Médio modalidade estudada no âmbito dessa pesquisa. a) a consolidação dos conhecimentos adquiridos no ensino fundamental; b) o prosseguimento dos estudos; c) o preparo pra o trabalho e a cidadania; d) o desenvolvimento de habilidades como continuar a aprender e) capacidade de se adaptar com flexibilidade às novas condições de adaptação de ocupação e aperfeiçoamento f) o aprimoramento do educando como pessoa humana, incluindo a formação ética e o desenvolvimento da autonomia intelectual e do pensamento crítico; e g) a compreensão dos fundamentos científico-tecnológicos dos processos produtivos, relacionando teoria e prática (PCN, 2000, p. 33).

Quando nos detemos nas normativas e diretrizes orientadoras dos currículos e no âmbito dessa pesquisa as orientações para a disciplina de educação física e direcionamos nosso olhar para a realidade do que é praticado e ensinado nas escolas, percebemos que há uma discrepância enorme entre a teoria e a prática e mais ainda que essa teoria mesmo que com poucas mudanças ainda reflete o aparato teórico que remonta aos meados do século XIX sob a égide de práticas que limitam o corpo e os movimentos a processos rígidos e fixos. Essas práticas corporais ainda trazem em seu escopo um distanciamento dos interesses dos alunos principalmente das escolas de ensino médio onde na escola pesquisada pude observar que, embora alguns professores busquem colocar em prática determinados exercícios com o intuito de formar o corpo dentro de uma concepção global de corpo integrado a maioria dos alunos vão gradativamente buscando outras formas e espaços de movimento e de práticas corporais que se diferenciam das praticadas nas escolas, seja em parques, praias, em clubes, praças, academias entre outros que vêm crescendo exponencialmente através desse grupo juvenil.

Situando a presente reflexão dentro dessa perspectiva, delimitaremos nosso lócus de pesquisa em duas escolas públicas delineando como estão sendo trabalhadas as práticas corporais em cada uma delas, focando o ponto de vista de discentes e docentes que espontaneamente participaram dessa pesquisa. Apresentaremos alguns pontos que foram traçados no sentido de responder os questionamentos que nortearam a pesquisa, tais como: relacionar os exercícios realizados durante as aulas de educação física; elencar a prática de jogos esportivos; discutir o ponto de vista dos professores de educação física e de alunos participantes e relacionar as atividades praticadas ao currículo escolar. 
Para a efetivação dos pontos ressaltados, trabalhamos com a técnica de observação participante e formação de grupo de discussão com os profissionais da área e discentes do ensino médio nas escolas observadas.

A pesquisa foi realizada em duas escolas públicas de Fortaleza, estado do Ceará- Brasil, sendo uma de Educação Fundamental e outra de Ensino Médio.

Com o entendimento de que, conforme cita Daolio (1984) as brincadeiras, os jogos, os esportes, a estética do corpo, tudo sofre influência direta da cultura, buscamos evidenciar o que permeia nossas escolas, no campo da educação física, embora a LDB proponha uma perspectiva de um corpo integrado, a realidade de nossa cultura escolar tradicional apresenta determinados conteúdos que veem nosso corpo como algo puramente biológico.

Essa visão minimalista é evidenciada principalmente no campo da educação física que vem postulando suas práticas em todas as etapas da educação básica. Alguns autores buscam em seus estudos e pesquisas construir uma orientação de educação física voltada para a saúde. Os Parâmetros Curriculares Nacionais (PCN) trazem um aparato teórico baseado nos estudos desses autores, uma linha de pensamento que se aprofunda no sentido de uma educação física atenta aos problemas do presente que não pode deixar de eleger como uma das suas orientações centrais, a educação para a saúde, relacionando-a à uma educação social contribuindo para uma vida criativa, produtiva através dessa educação (PCN, 2000). As observações e discussões nos grupos de discussão se pautaram sobre estas orientações e sobre as práticas realizadas nas duas escolas pesquisadas.

A pesquisa demarcou as práticas corporais e suas relações com os aportes teóricos aqui discutidos o que nos chama atenção para as similitudes dessas práticas com o projeto societário, político, que estabelece as relações de poder, onde a liberdade é limitada pelo tempo e espaço de modo a conformar os comportamentos e as posições sociais.

Na educação infantil, "recreação" é o termo comumente utilizado para denominar o espaço de tempo que o professor da educação infantil ou o recreador fica com as crianças em determinados espaços, geralmente pátio ou quadra de esportes, parques e outros, trabalhando jogos, brincadeiras entre outras atividades previamente ou não, planejadas para este momento.

Nestas observações elencamos um conjunto de práticas corporais que são comumente trabalhadas na educação infantil e realizadas no âmbito educacional e onde percebemos o caráter bastante intenso do universo cultural e limitado nessas práticas impressa pelos professores, considerando ainda que nenhum deles possuem formação acadêmica para a atividade que desempenham nessa área. Na Escola pública de Educação Infantil do Município de Fortaleza, no estado do Ceará, Brasil, observamos que as atividades mais trabalhadas são: 
1) Jogos com bola;

2) Saltos de obstáculos;

3) Corridas;

4) Passa bastão;

5) Polichinelo;

6) Brincadeiras de roda;

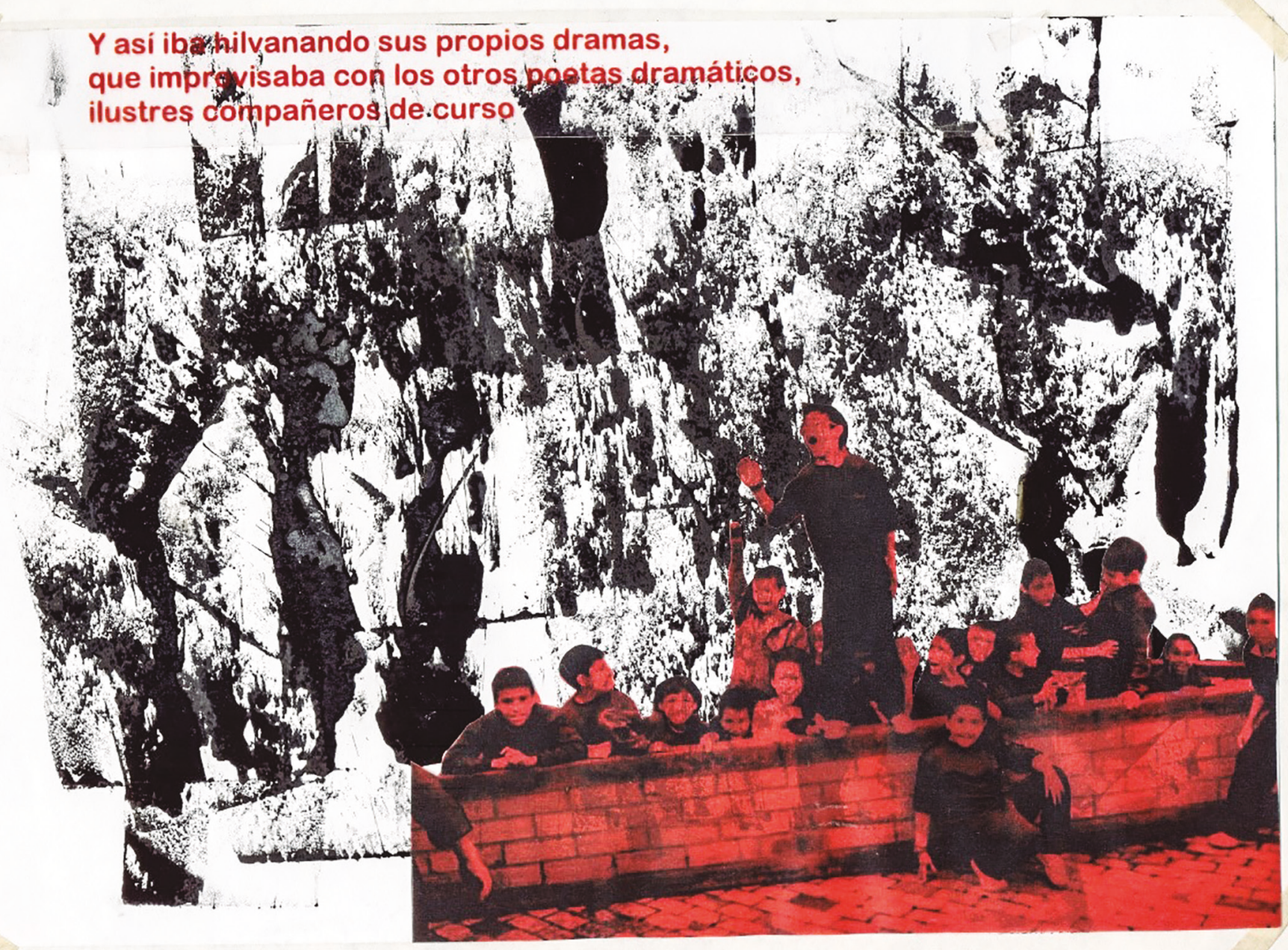


A escola observada possui espaço limitado para a prática de atividades recreativas e não possui quadra esportiva.

Durante as observações in loco, detectamos que na maioria das práticas realizadas:

1) Os meninos são separados das meninas;

2) Como não existe a exigência de um uniforme, as crianças vão com roupas usuais e meninas que estão de saia ou vestido não realizam determinadas atividades;

3) Existem atividades próprias para meninos e outras para as meninas;

4) As crianças que são de lares evangélicos não participam das atividades que envolvem danças ou não participam da recreação.

Ao conversarmos com os professores da educação infantil e mediante as observações coletadas, percebemos a influência da bagagem cultural que traz o professor ao ministrar as atividades corporais, limitando-se ao seu padrão cultural, sua forma de pensar, agir e ser na sociedade. O que nos faz refletir que esta limitação de trabalho com o corpo reafirma o pensamento de Foucualt (2009) acerca do disciplinamento que "cria entre os indivíduos um laço 'privado' que é uma relação de limitações (...) a maneira como é imposta e os mecanismos que a faz funcionar, tornando possível a subordinação de uns em relação aos outros que determina o "mais poder" e que, portanto, corrobora com a estigmatização e reforça os processos de desigualdades entre homens e mulheres, "fortes e fracos" etc.

Essa limitação também é corroborada por parte das universidades que não preparam profissionais para o desempenho de atividades alternativas, que visem transcender os currículos tradicionais. Ao se referir ao trabalho do professor de educação física, os PCNs (2000) ressaltam, que, mesmo quando esse profissional adquire uma bagagem de conhecimentos relevante na sua formação acadêmica, ocorre na escola um empobrecimento do seu trabalho "ao não resgate do que aprendeu, ao esquecimento, à subutilização de seu potencial" ao desestímulo que acabam por descaracterizar suas potencialidades que poderiam ser melhor desenvolvidas no ambiente educacional.

A cultura arraigada desde o nascimento e preservada pela forma de vida cotidiana dos professores segue prevalecendo fortemente sobre sua prática docente. As atividades são preparadas ainda seguindo técnicas que denotam certa rigidez até mesmo com as crianças da educação infantil.

Na escola Estadual de Ensino Médio, observamos uma cultura muito mais de jogos, prevalecendo a divisão entre homens e mulheres e a prática de jogos para homens e outros para as mulheres. Aqui mas, uma vez podemos ressaltar o emprego de uma cultura machista presente no Nordeste e em nosso estado Ceará e que é refletido nas atitudes e modos de trabalhar a prática da educação física, acentuando ainda mais as diferenças regionais, as questões de gênero e os mecanismos de poder que já se inserem no cotidiano escolar. 
Nessa prática observada exemplificaremos algumas modalidades de jogos com bola onde o professor se limita a dar o comando das atividades. Os mais praticados são:
1) Futebol;
2) Voleibol;
3) Carimba (jogo com bola muito apreciado no Ceará);
4) Basquete e
5) Handebol.

Estas modalidades se apresentam com características bastante definidas e se limitam ao estilo já tão difundido em nossa sociedade, que não apresentam nenhuma característica diferenciada que possa superar o processo da aplicabilidade da educação física de um modo libertário, muito pelo contrário, segue o padrão da disciplina como uma modalidade em que se exerce o poder e comporta todo um conjunto de procedimentos que vai estabelecer os comportamentos sociais.

Desse modo a educação física aplicada também no Ensino Médio, vai trazer em seu escopo atividades alheias ao aprofundamento das questões sociais relacionadas à criação e a produção de caráter coletivo, que poderiam orientar aos educandos um pensamento mais reflexivo, no entanto, elencando as atividades observamos:

-O futebol é frequentado pela maioria de meninos;

-O voleibol consiste no feminino e no masculino;

-Basquete é uma modalidade frequentada em sua maioria por meninos, tendo em vista que a maioria das meninas são de estatura baixa o que caracteriza uma diferença regional e que com essa prática é acentuada;

-O handebol é composto por meninas e o carimba é uma modalidade apreciada por meninas e por um grupo de homossexuais e que dificilmente comporta em sua prática os meninos (héteros).

-Outras práticas corporais observadas se resumem em corridas, alguns exercícios de alongamento e de respiração. 
Nesse tocante referenciamos o pensamento de Daolio (1984), quando coloca que a prática da educação física contemporânea segue limitada compreendendo o corpo, como um elemento que se traduz em estética a partir da utilização de determinadas técnicas que objetivam desenvolver postura correta, forma de andar, movimentos uniformes, sincronizados e graciosos que reverberam no comportamento social.

Estas observações nos permitem perceber a relação existente entre corpo, história, corpo e cultura, corpo e sociedade permeando as pedagogias, o currículo, a formação docente e se traduzindo em prática no âmbito de cada escola.

\section{Considerações finais}

O artigo apresentado trouxe um enfoque das práticas corporais desenvolvidas nas escolas públicas do município de Fortaleza, estado do Ceará no Brasil sob a ótica histórica, social e cultural, que, imprimem no corpo elementos significativos que passam a ser expressos por este corpo através de gestos, posturas, forma de andar dentre outras e se amplia pelos sentidos e comportamentos humanos.

Partes desses significados são absorvidos através dessas práticas que começam a ser trabalhadas na escola desde a infância na educação infantil onde, como pudemos detectar, sofrem a influência direta dos processos históricos, culturais e sociais vivenciados pelos profissionais da educação física e reforçados nos cursos e Universidades por onde passam esses profissionais, aliado aos conhecimentos que são parte do currículo acadêmico e que, ainda seguem padrões estereotipados e em conformidade dados históricos que se consolidaram a partir do século XIX, sob os marcos da ciência positivista (Soares, 2005) se fortalecendo na visão minimalista da biologia sendo esta, segundo Daolio (1984) a perspectiva que ainda vigora na contemporaneidade.

Com o intuito de situar uma reflexão sobre as práticas corporais dentro da perspectiva histórico e social ressaltamos os conceitos de "corpo educado", "corpo moldado" e "corpo adestrado" apresentados por Soares (2005), que permearam o arcabouço teórico da pesquisa, no sentido de fomentar a compreensão acerca dos processos históricos e sociais que gestaram a educação física nos moldes atuais, de refletir sobre o papel do profissional de educação física e, consequentemente, na aplicação das práticas corporais no contexto da escola.

A partir das observações coletadas na pesquisa podemos concluir que:

1) O corpo ainda é trabalhado sob uma perspectiva puramente biológica;

2) Nas práticas corporais trabalhadas pelos professores prevalece o entendimento que 
o professor traz de recreação e de ginástica;

3) No planejamento dos professores não ocorrem orientações para a prática dos trabalhos corporais;

4) A maioria dos professores da educação infantil não possui formação acadêmica para o trabalho com o corpo;

Nas atividades realizadas na educação física destacam-se problemáticas de questões de gênero, orientação sexual e traços da cultura local, regional e nacional.

Nas práticas esportivas:

1) O futebol é o jogo que se destaca perante os demais;

2) O carimba é uma modalidade tipicamente cearense é preferencial entre as meninas;

3) Ocorre separação entre meninos e meninas, o que denota forte traço do regionalismo machista do Nordeste;

4) A estatura também é uma característica que determina a prática esportiva adotada;

Denotam-se dificuldades dos profissionais trabalharem com questões de gênero e orientação sexual.

Nossa análise ressalta que, em virtude dessas limitações, a juventude que frequenta nossas escolas e que são vítimas de todos os tipos de preconceitos e discriminações sociais não encontram nas instituições educacionais públicas espaço de identidade, de possibilidade de transgressão e de discussão sobre suas subjetividades, seus sonhos, seus anseios, tendo os mesmos que submeterem-se ao que está posto, determinado, bastando a eles absorverem o que está sendo repassado e nesse processo acabam por reproduzir e acentuar o círculo vicioso de exclusão social que os mantém.

Concluímos também que a prática da educação física ainda permanece muito limitada à um currículo tradicional que prioriza a técnica e trabalha dentro de uma perspectiva minimalista de corpo. Podemos ainda ressaltar que não é mais possível se pensar o corpo fora de um contexto holístico, que considere o ser humano em sua integralidade, sob pena de perder sua totalidade e sua conexão com o mundo a sua volta. Há necessidade latente de se repensar os currículos, bem como as formações desses profissionais tanto no nível de graduação, formação continuada e de pós-graduação, no sentido de atender as atuais aspirações dos alunos numa proposta que considere o ser humano 
em sua coletividade, e não mais no sentido de perpetuar modelos que priorizam a estética, o adestramento, e que acabam por reproduzir os conceitos e preconceitos, acentuando as desigualdades e limitando capacidades do ser humano se reinventar.

Não podemos mais partir de interpretações de processos unidimensionais que balizam as práticas educacionais, é necessário, portanto, se pensar o corpo sob uma perspectiva holística, cujo estudante é visto como uma pessoa global com corpo, mente, emoções e espírito (Yus, 2002, p. 16), para J. Miller (1996) esta perspectiva está nas relações entre o pensamento linear e a intuição, entre a mente e o corpo e necessita de um currículo também redimensionado. É imperativo, portanto, transcender o currículo convencional, no sentido de adquirir autonomia, transgredir regras impostas e conquistar uma liberdade que se ampara pelo cuidado do corpo enquanto indivíduo e enquanto ser social.

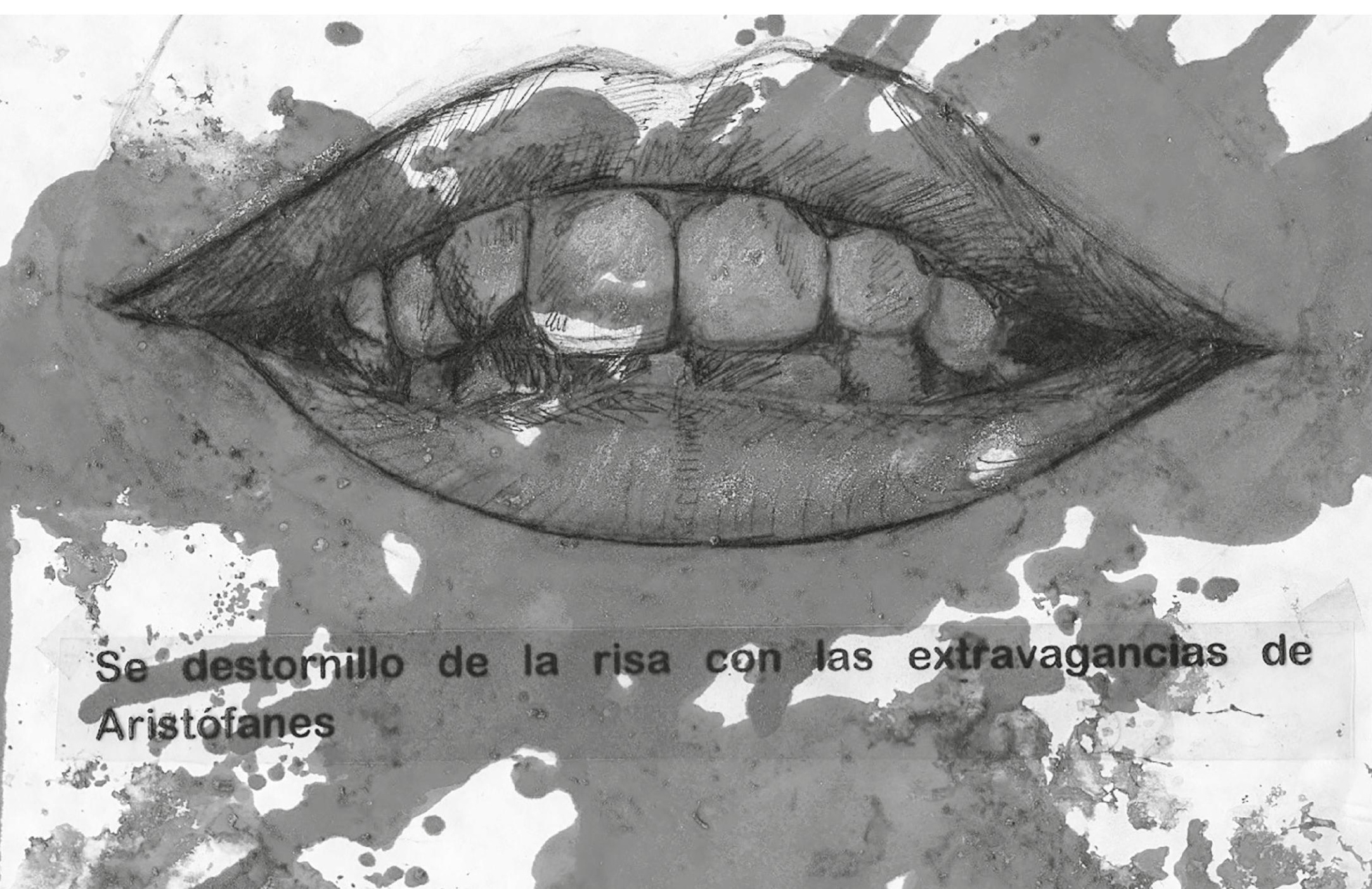




\section{Referencias}

Daolio, J. (2004). Educação Física e o Conceito de Cultura, Campinas, S. Paulo, Editora: Autores Associados.

Elias, N. (1993). O Processo Civilizador- Vol 2, Formação do Estado e Civilização, Rio de Janeiro, Editor: Jorge Zahar.

Foucault, Michel. (2009). Vigiar e punir: nascimento da prisão; tradução de Raquel Ramalhete. 37. ed. Petropólis, R,J. Vozes

Kofes, S.E. (1985). Sobre o corpo, não é o próprio corpo que fala? Ou o discurso desse corpo sobre o qual se fala. IN: BRUHNS, H.T

(org.). Conversando Sobre o Corpo. Campinas, S.P. Papirus.

Soares, C. L. (2005). Imagens da Educação No Corpo: estudo a partir da ginástica francesa no século XIX/ 3. Ed. Campinas, S.P. Autores Associados.

Soares, C. L. (1994). Educação Física: raízes europeias e Brasil. Campinas, S.P. Veiga-Neto, A. (2016). Foucault \& a Educação. 3. Ed; Belo Horizonte: Autêntica Editora.

Yus, R. (2002). Educação Integral: uma educação holística para o século XXI/ Rafael Yus; trad. Daisy Vaz de Moraes. - Porto Alegre: Artmed.
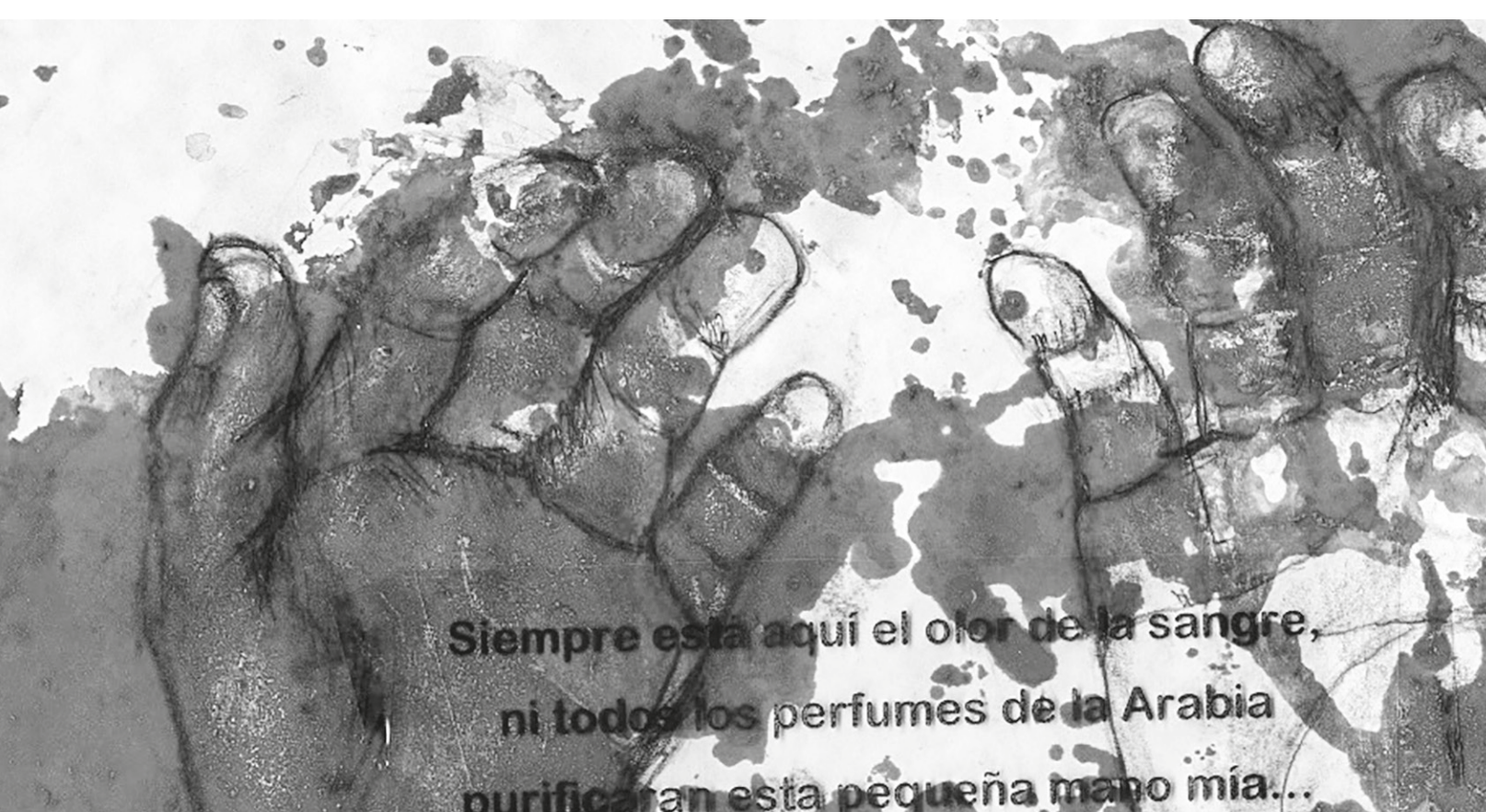
